\title{
Xanthogranulomatous Osteomyelitis of the Tibia
}

\author{
Saeed Solooki, MD, ${ }^{1}$ Amir Human Hoveidaei, MD, ${ }^{2,3}$ Bahareh Kardeh, MD, ${ }^{4}$ Negar Azarpira, MD, ${ }^{5}$ Ehsan Salehi, MD ${ }^{1}$ \\ ${ }^{1}$ Department of Orthopedic Surgery, Bone and Joint Diseases Research Center, Shiraz University of Medical Sciences, Shiraz, Iran ${ }^{2}$ Student \\ Research Committee, Shiraz University of Medical Sciences, Shiraz, Iran ${ }^{3}$ Students' Scientific Research Center, Tehran University of \\ Medical Sciences, Tehran, Iran ${ }^{4}$ Bone and Joint Diseases Research Center, Clinical Neurology Research Center, Shiraz University of \\ Medical Sciences, Shiraz, Iran ${ }^{5}$ Transplant Research Center, Shiraz University of Medical Sciences, Shiraz, Iran
}

Background: Xanthogranulomatous osteomyelitis $(\mathrm{XO})$ is a rare chronic inflammatory process that is histologically characterized by the presence of foamy macrophages, histiocytes, and plasma cells. Radiologic and gross examinations can mimic malignancy, so definitive diagnosis should be made by histopathologic evaluation.

Case Report: A 15-year-old male presented with pain in the proximal right leg for 2 weeks prior to admission. The patient had a history of leg trauma 3 years prior that was responsive to as-needed analgesics. Laboratory data revealed increased erythrocyte sedimentation rate and C-reactive protein. X-ray of the right tibia showed a periosteal reaction and bulging of bone with a questionable destruction of the cortex. Magnetic resonance imaging demonstrated an expansile bony lesion in the proximal metaphysis of the tibia. Histopathologic examination showed the bone trabecula surrounded by chronic inflammatory cells and a fragment of dead bone surrounded by histiocytes, foamy macrophages, and plasma cells. The pathologist confirmed the diagnosis of XO. Wound culture proved moderate growth of Staphylococcus aureus, and treatment with cefazolin and cephalexin was successful.

Conclusion: The patient was not treated with the routine therapy used in previously reported cases (curettage), suggesting that antibiotic therapy should be considered before employing surgical interventions for $\mathrm{XO}$.

Keywords: Bone diseases, infection, osteomyelitis, tibia, xanthomatosis

Address correspondence to Amir Human Hoveidaei, MD, Student Research Committee, $2^{\text {nd }}$ floor, Building of Shiraz University of Medical Sciences, Neshat St., Shiraz, Iran. Tel: +98-71-32122970. Email: a.h.hoveidaei@sums.ac.ir

\section{INTRODUCTION}

Xanthogranulomatous process is a rare form of chronic inflammation that is histologically characterized by the presence of foamy periodic acid-Schiff-positive histiocytes admixed with plasma cells and lymphocytes. This condition is predominantly observed in soft tissues and has been described in the gallbladder, kidney, lung, and gastrointestinal and urogenital tracts. Bone involvement is less common. ${ }^{1-4}$ Cozzutto initially coined the term xanthogranulomatous osteomyelitis (XO) in $1984 .^{5}$ To the best of our knowledge, only 20 cases of $X O$ have been reported since. We report a case of $\mathrm{XO}$ of the tibia in a young male.

\section{CASE REPORT}

A 15-year-old male with body weight of $65 \mathrm{~kg}$ and height of $160 \mathrm{~cm}$ was referred to our orthopedic center with the chief complaint of pain in the proximal right leg for the previous 2 weeks. On physical examination, the patient had tenderness, swelling, and erythema in the area. The patient reported a history of direct trauma to his right leg 3 years prior during a football game by one of the opposing team's players. The trauma was not severe and responded well to as-need oral analgesics, so the patient had not had the injury evaluated by a physician.
Laboratory investigation showed an elevated erythrocyte sedimentation rate (ESR) of $57 \mathrm{~mm} / \mathrm{hr}$ (normal range, 0-20 mm/hr) and a C-reactive protein (CRP) level of $105 \mathrm{mg} / \mathrm{L}$ (normal range, $\leq 12 \mathrm{mg} / \mathrm{L}$ ). Total leukocyte count and differential were within normal ranges; however, mild anemia was detected (red blood cells of 5.14 million/L, hemoglobin of $12.3 \mathrm{~g} / \mathrm{dL}$, and mean corpuscular volume of $74.9 \mathrm{fL}$ ). Renal and liver function tests were normal. Chest $\mathrm{x}$-ray was negative.

X-ray of the right tibia showed a periosteal reaction and bulging of the bone with a questionable destruction of the cortex (Figure 1). Magnetic resonance imaging revealed a $60 \times 30 \mathrm{~mm}$ expansile bony lesion in the proximal metaphysis of the tibia, suggestive of osteomyelitis with abscess formation, Ewing sarcoma, or osteosarcoma (Figure 2). Bone scan exhibited increased uptake in the proximal right tibia.

The lesion was biopsied. Purulent discharge and multiple bony fragments with a creamy-gray color were grossly visible. Histopathologic examination showed the bone trabecula surrounded by chronic inflammatory cells and a fragment of dead bone surrounded by histiocytes, foamy macrophages, and plasma cells (Figures 3 and 4). The pathologist confirmed the diagnosis of $\mathrm{XO}$. 


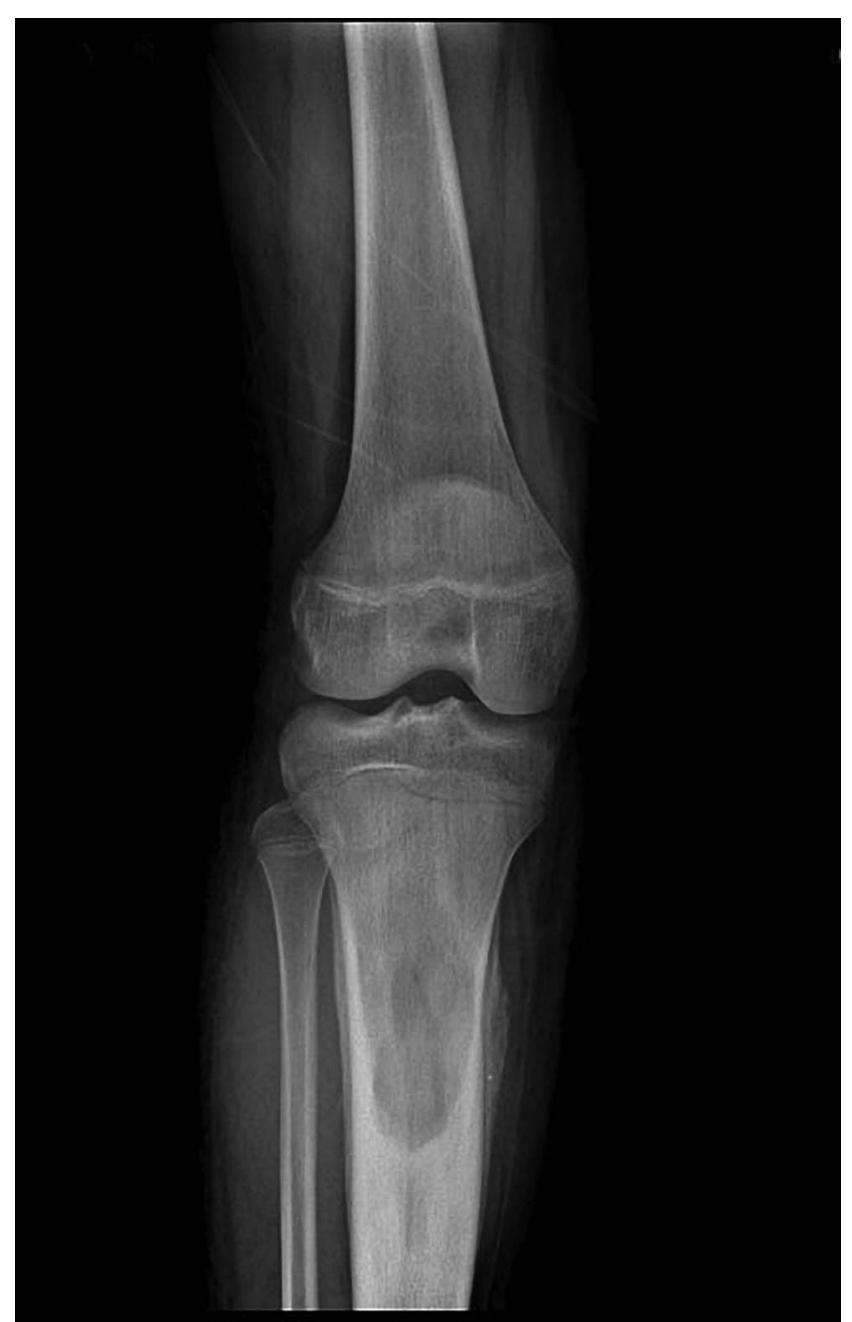

Figure 1. X-ray on the day of admission showed periosteal reaction and bulging of the bone with a questionable destruction of the cortex.

After biopsy demonstrated the infectious nature of the lesion, microbiologic assessment was requested, and the patient was administered intravenous (IV) cefazolin 500 mg every 8 hours and gentamicin $40 \mathrm{mg}$ every 8 hours. Qualitative polymerase chain reaction was negative for tuberculosis. Wound culture proved moderate growth of

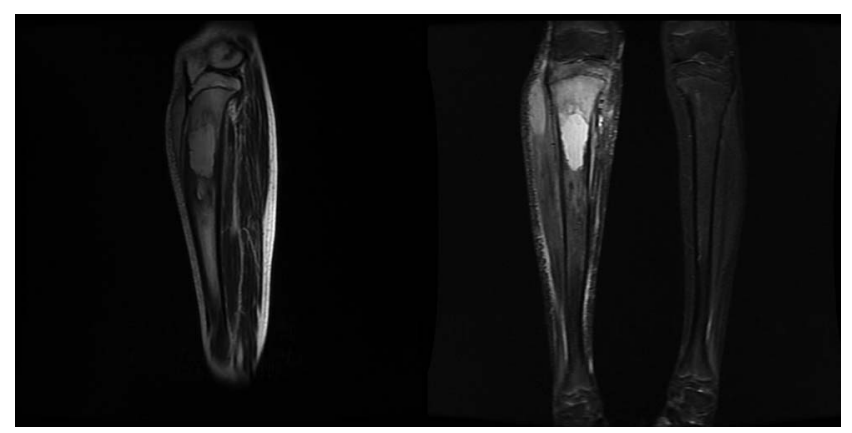

Figure 2. Magnetic resonance imaging revealed an expansile bony lesion in the proximal metaphysis of the tibia.

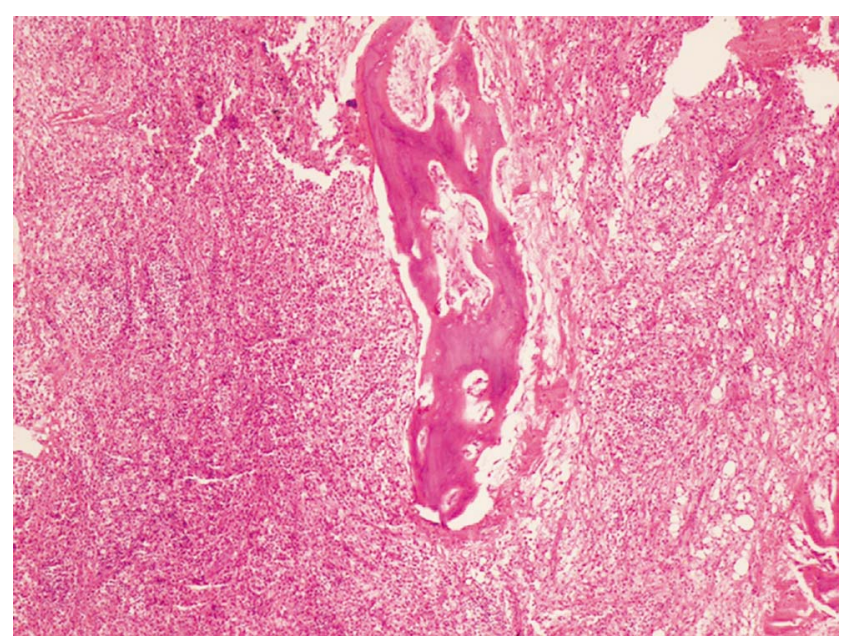

Figure 3. Lesion biopsy showed the bone trabecula surrounded by chronic inflammatory cells.

Staphylococcus aureus that was sensitive to cefazolin and cephalexin. When these results were received after 12 days, gentamicin was changed to cephalexin $1 \mathrm{~g}$ IV every 8 hours, and cefazolin was continued at the same dosage and interval for 9 more days.

The patient's condition gradually improved during his hospital stay, and he was discharged on oral cephalexin and clindamycin for 3 weeks.

During the patient's 3-week admission, he received IV gentamicin for 12 days (which was not the proper choice according to the antibiogram), IV cefazolin for 21 days, IV cephalexin for 9 days, and oral cephalexin and clindamycin for 21 days.

At 11-week follow-up, the patient's symptoms had completely resolved. X-ray of the right tibia did not indicate any recurrence (Figure 5). In conjunction with the absence of symptoms, consecutive results of $0 \mathrm{~mm} / \mathrm{hr}$ for ESR and $1 \mathrm{mg} / \mathrm{L}$ for CRP level at 11, 19, and 25 weeks of follow-up confirmed the success of the treatment.

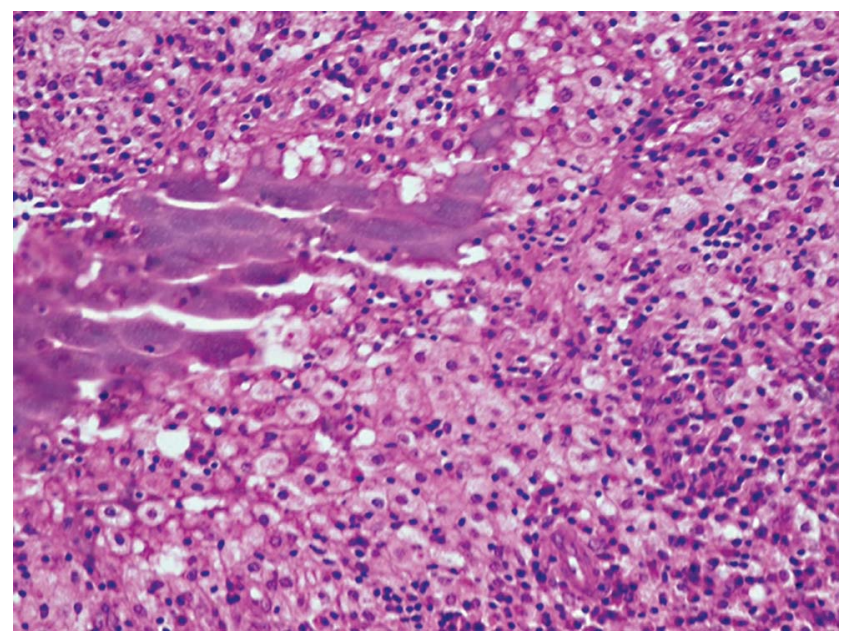

Figure 4. Lesion biopsy showed a fragment of dead bone surrounded by histiocytes, foamy macrophages, and plasma cells. 


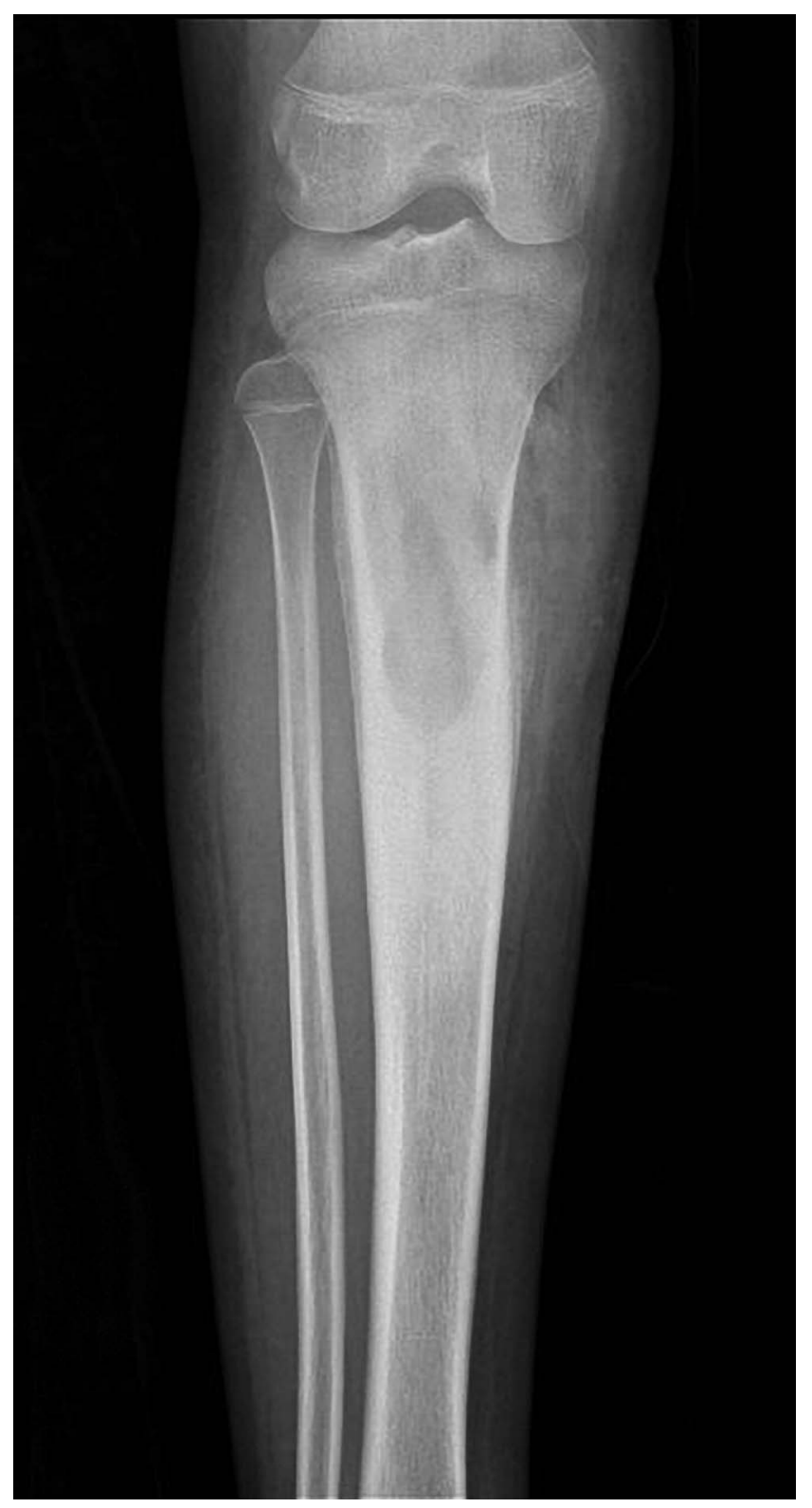

Figure 5. Follow-up x-ray after 11 weeks showed no bone bulging or periosteal reaction.

\section{DISCUSSION}

XO was first introduced in the reports of 2 cases in 1984 followed by reports of 18 other patients summarized in the Table. $^{5-22}$ A review of these 20 cases and the case of our patient suggests that $X O$ is more prevalent in males (15 of 21) than females and has no characteristic age distribution. Most patients (17 of 21 ) had unifocal $\mathrm{XO}$; only 4 had multifocal lesions. ${ }^{7,10,17,20}$ The most commonly affected sites are the long tubular bones (17 of 21). As with our patient, pain and swelling of the involved bone seem to be the primary reason for presentation. ${ }^{5-22}$

Cheema et al attributed the pathogenesis of xanthogranulomatous process in bone to a delayed-type hypersensitivity reaction of cell-mediated immunity. ${ }^{22}$ Trauma has been also mentioned as a hypothetical reason for this process. In addition to our case, 2 other patients with $\mathrm{XO}$ had a history of trauma. ${ }^{6,10}$ Trauma also seems to play a role in the development of xanthogranulomatous process in organs; Franco et al reported the role of gallstone trauma in inducing xanthogranulomatous cholecystitis. ${ }^{23}$ In some cases of $\mathrm{XO}$, the bacterial organisms Mycobacterium marinum, ${ }^{7} \mathrm{~S}$ aureus, ${ }^{9,11}$ and $P$ seudomonas ${ }^{15}$ have been detected in specimen cultures; in our case, the culture was positive for $S$ aureus. The association between bacterial infections and xanthogranulomatous lesions in the bone may become established as a probable etiopathogenesis, as with other organs. ${ }^{20}$

Given the possibility of multicentric lesions, whole-body radiologic analysis is recommended for a patient with confirmed $\mathrm{XO}$; however, diagnosing $\mathrm{XO}$ with imaging is challenging. ${ }^{21}$ Radiologically and grossly, XO manifests as mass-like lesions mimicking infiltrative malignant tumors. Thus, differentiating this pseudoneoplasm of infectious etiology from true malignancy is a crucial step for implementing timely and appropriate management. Clinical background that includes history of trauma, radiographic evaluation, and histopathologic examination are essential diagnostic components.

Differential diagnoses of $\mathrm{XO}$ include the following:

1. Langerhans cell histiocytosis $(\mathrm{LCH})$ : $\mathrm{LCH}$ lesions consist of Langerhans cells with eosinophil infiltration. Radiographically, LCH usually has circumscribed lytic bony lesions without surrounding sclerosis. ${ }^{24}$

2. Xanthoma: Xanthoma can occur in the bone secondary to hyperlipidemia; however, xanthoma may not show suppurative inflammation. ${ }^{25}$

3. Erdheim-Chester disease (ECD): ECD is a multifocal disorder with frequent involvement of extraskeletal tissues; histology shows foamy histiocytes, fibrosis without neutrophilic infiltrations, and cholesterol clefts. ${ }^{26}$

4. Malakoplakia: In patients with malakoplakia, the histologic examination shows large foamy macrophages and Michaelis-Gutmann bodies. ${ }^{27}$

5. Infiltrative lipid storage diseases: Clinical background (including muscle atrophy, cardiomyopathy, and dysfunction of internal organs), foamy macrophages of the bone marrow, and the absence of suppurative inflammation can help differentiate infiltrative lipid storage diseases from $\mathrm{XO} .^{28}$

6. Metastatic renal cell carcinoma: Metastatic renal cell carcinoma can be easily differentiated from $\mathrm{XO}$ by history taking and histologic tumor patterns. ${ }^{29}$

7. Chronic recurrent multifocal osteomyelitis (CRMO): CRMO is an autoinflammatory disease that usually occurs in a multicentric manner in the long bones and the shoulder girdle during childhood. The radiologic findings of CRMO are osteolytic initially but later demonstrate a hyperostotic and sclerotic state. ${ }^{30}$

8. Fibrohistiocytic tumor: Fibrohistiocytic tumors are composed of cells that have morphologic features of fibroblasts and histiocytes. However, these cells are not histiocytes and may exhibit phagocytic properties, including neutrophil phagocytosis. ${ }^{4,31}$

Because of the rarity of $\mathrm{XO}$, no uniform treatment protocol is available. Most cases report treatment with curettage and bone grafting. Antibiotics were prescribed in addition to surgical procedures (synovectomy and arthrodesis) 


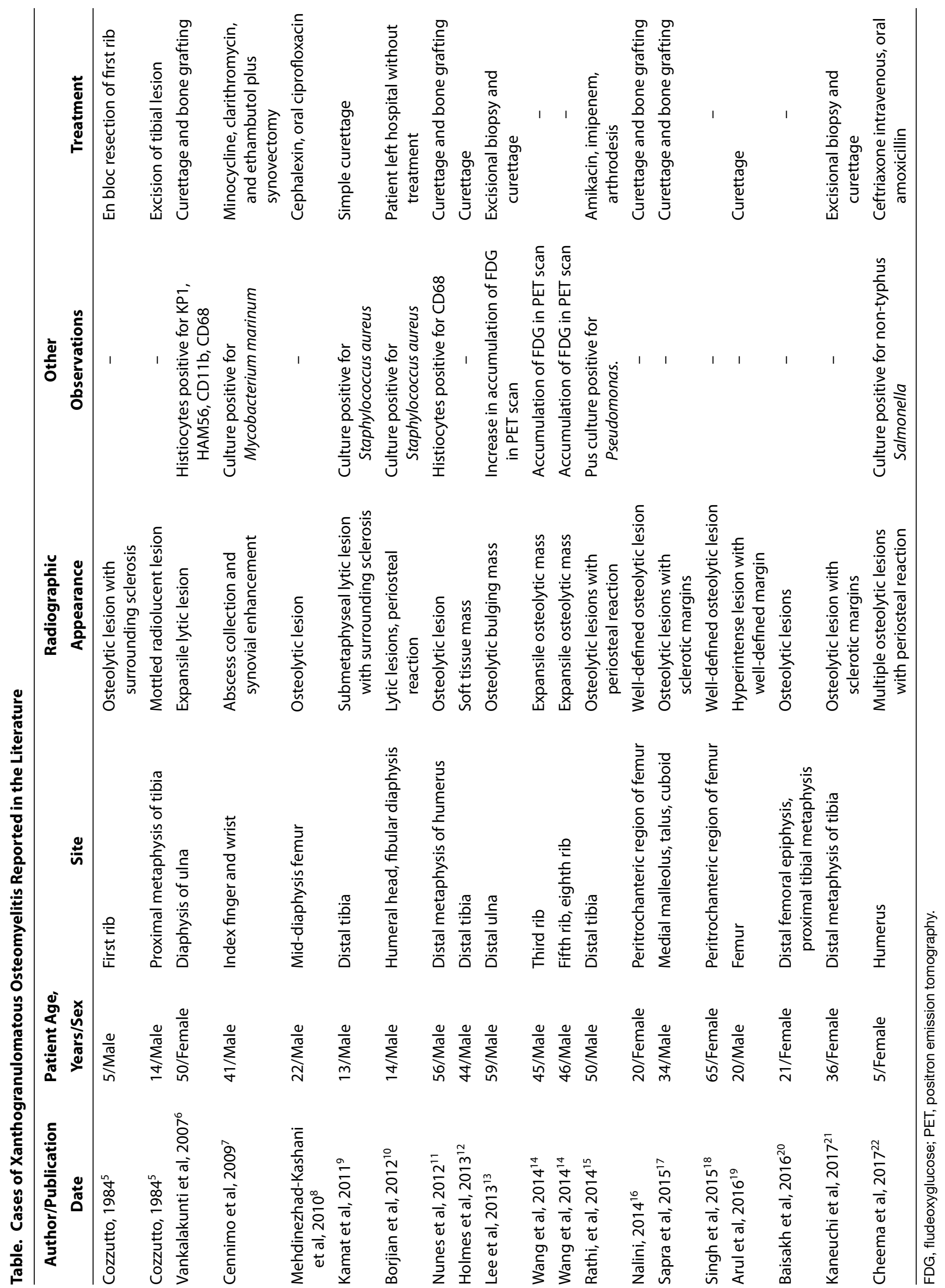


for 2 patients. ${ }^{7,15}$ For 2 patients in addition to our case, treatment was completely based on antibiotics with regular follow-up. 8,22

Although recommending the omission of surgical treatment is not possible, the authors do recommend requesting microbiologic assessment for all lesions with an infectious nature. Treatment with wide-spectrum antibiotics followed by treatment with definitive effective antibiotics is the best choice, followed by regular physical examination and laboratory follow-up, including ESR and CRP.

Based on 3 reported cases (including ours), ${ }^{8,22}$ a key point in the treatment of $\mathrm{XO}$ is to consider using antibiotic therapy as a noninvasive treatment before surgical intervention.

\section{CONCLUSION}

We report a case of $\mathrm{XO}$ because of its rarity, importance, and curability. While $\mathrm{XO}$ is benign, it can mimic malignant primary or secondary bone lesions in its clinical manifestations, gross examination, and imaging. Hence, clinicians and radiologists must be aware of $\mathrm{XO}$ and include it in their differential diagnosis.

\section{ACKNOWLEDGMENTS}

The authors have no financial or proprietary interest in the subject matter of this article.

The authors would like to thank Shiraz University of Medical Sciences, Shiraz, Iran, the Center for Development of Clinical Research of Nemazee Hospital, and Dr Nasrin Shokrpour for editorial assistance.

\section{REFERENCES}

1. Ballentine WK 3rd, Vilson F, Dyer RB, Mirzazadeh M. Nephron-sparing management of xanthogranulomatous pyelonephritis presenting as spontaneous renal hemorrhage: a case report and literature review. BMC Urol. 2018 Jun 5;18(1):57. doi: 10.1186/s12894-018-0354-3.

2. Guzmán-Valdivia G. Xanthogranulomatous cholecystitis: 15 years' experience. World J Surg. 2004 Mar;28(3):254-257. doi: 10.1007/s00268-003-7161-y.

3. Bourm KS, Menias CO, Ali K, Alhalabi K, Elsayes KM. Spectrum of xanthogranulomatous processes in the abdomen and pelvis: a pictorial review of infectious, inflammatory, and proliferative responses. AJR Am J Roentgenol. 2017 Mar;208(3):475-484. doi: 10.2214/AJR.16.17075.

4. Cozzutto C, Carbone A. The xanthogranulomatous process. Xanthogranulomatous inflammation. Pathol Res Pract. 1988 Aug;183(4):395-402. doi: 10.1016/S0344-0338(88)80085-2.

5. Cozzutto C. Xanthogranulomatous osteomyelitis. Arch Pathol Lab Med. 1984 Dec;108(12):973-976.

6. Vankalakunti M, Saikia UN, Mathew M, Kang M. Xanthogranulomatous osteomyelitis of ulna mimicking neoplasm. World J Surg Oncol. 2007 Apr 30;5:46. doi: 10.1186/1477-7819-5-46.

7. Cennimo DJ, Agag R, Fleegler E, et al. Mycobacterium marinum hand infection in a "sushi chef". Eplasty. 2009 Oct 14;9:e43.

8. Mehdinezhad-Kashani M, Zarif-Zakerian B, Shayan K, Riyasi F. Xanthogranulomatous osteomyelitis of femur (report of one case). Iran J Orthop Surg. 2010;8(33):187-190.

9. Kamat G, Gramapurohit V, Myageri A, Shettar C. Xanthogranulomatous osteomyelitis presenting as swelling in right tibia. Case Rep Pathol. 2011;2011:257458.

doi: $10.1155 / 2011 / 257458$.
10. Borjian A, Rezaei F, Eshaghi MA, Shemshaki H. Xanthogranulomatous osteomyelitis. J Orthop Traumatol. 2012 Dec;13(4):217-220. doi: 10.1007/s10195-011-0165-8.

11. Nunes R, Costa J, Martins M. Osteomielite xantogranulomatosa do úmero. Rev Port Ortop Traum. 2012;20(4):459-464.

12. Holmes BJ, Castelino-Prabhu S, Rosenthal DL, Ali SZ. Xanthogranuloma of bone: a challenging imitator of malignancy. Acta Cytol. 2013;57(2):198-202. doi: 10.1159/000345900.

13. Lee $\mathrm{SH}$, Lee $\mathrm{YH}$, Park $\mathrm{H}$, et al. A case report of xanthogranulomatous osteomyelitis of the distal ulna mimicking a malignant neoplasm. Am J Case Rep. 2013;14:304-307. doi: 10.12659/AJCR.889422.

14. Wang YL, Yu H, Zhang H, Cui XJ, Han JK. Xanthogranulomatous osteomyelitis of rib mimicking malignant lesions in (18)F-FDG PET/CT imaging: a report of two cases. Clin Nucl Med. 2014 May;39(5):e315-e317. doi: 10.1097/RLU.0b013e3182a20d45.

15. Rathi M, Khattri J, Budania SK, Singh J, Awasthi S, Verma S. Xanthogranulomatous osteomyelitis. Arch Med Health Sci. 2014;2(2):228. doi: 10.4103/2321-4848.144352.

16. Nalini G. Xanthogranulomatous osteomyelitis: a case report. Med J. 2014;1(6):45-47.

17. Sapra R, Jain P, Gupta S, Kumar R. Multifocal bilateral xanthogranulomatous osteomyelitis. Indian J Orthop. 2015 Jul-Aug;49(4):482-484. doi: 10.4103/0019-5413.159682.

18. Singh S, Batra S, Maini L, Gautam VK. Xanthogranulomatous osteomyelitis of proximal femur masquerading as benign bone tumor. Am J Orthop (Belle Mead NJ). 2015 Aug;44(8): E272-E274.

19. Kaneuchi Y, Tajino T, Hakozaki M, et al. Xanthogranulomatous osteomyelitis of the distal tibia: a case report. Int J Rheum Dis. 2017 Dec;20(12):2238-2241. doi: 10.1111/1756-185X.12817.

20. Arul P, Ramdas A, Varghese R, Kanchana B. Xanthogranulomatous osteomyelitis of femur masquerading as neoplasm. Clin Cancer Investig J. 2016;5(2):163. doi: 10.4103/2278-0513.177134.

21. Baisakh MR, Kar MR, Agrawal A, Mohapatra N. Xanthogranulomatous osteomyelitis mimicking neoplasm: a rare entity. Indian J Pathol Microbiol. 2016 Apr-Jun;59(2):253-254. doi: 10.4103/0377-4929.182016.

22. Cheema A, Arkader A, Pawel B. Xanthogranulomatous osteomyelitis of the humerus in a pediatric patient with Alagille syndrome: a case report and literature review. Skeletal Radiol. 2017 Oct;46(10):1447-1452. doi: 10.1007/s00256-017-2707-5.

23. Franco V, Aragona F, Genova G, Florena AM, Stella M, Campesi G. Xanthogranulomatous cholecystitis. Histopathological study and classification. Pathol Res Pract. 1990 Jun;186(3):383-390. doi: 10.1016/S0344-0338(11)80297-9.

24. Azouz EM, Saigal G, Rodriguez MM, Podda A. Langerhans' cell histiocytosis: pathology, imaging and treatment of skeletal involvement. Pediatr Radiol. 2005 Feb;35(2):103-115. doi: 10.1007/s00247-004-1262-0.

25. Ahmed G, Al Dosari M, El-Mahi M, Abolfotouh SM. Primary xanthoma of calcaneus bone: case report. Int J Surg Case Rep. 2014;5(10):699-702. doi: 10.1016/j.jjscr.2014.07.016.

26. Yun EJ, Yeh BM, Yabes AP, Coakley FV, Kane CJ. Erdheim-Chester disease: case report and review of associated urological, radiological and histological features. J Urol. 2003 Apr;169(4):1470-1471. doi: 10.1097/01.ju.0000053930.11034.8c.

27. McClure J. Malakoplakia. J Pathol. 1983 Aug;140(4):275-330. doi: 10.1002/path.1711400402.

28. Ferreira CR, Gahl WA. Lysosomal storage diseases. Trans/ Sci Rare Dis. 2017 May 25;2(1-2):1-71. doi: 10.3233/TRD-160005. 
29. Umer M, Mohib Y, Atif M, Nazim M. Skeletal metastasis in renal cell carcinoma: a review. Ann Med Surg (Lond). 2018 Jan 31;27:9-16. doi: 10.1016/j.amsu.2018.01.002.

30. Björkstén B, Boquist L. Histopathological aspects of chronic recurrent multifocal osteomyelitis. J Bone Joint Surg Br. 1980 Aug;62(3):376-380. doi: 10.1302/0301-620X.62B3.7410472.

This article meets the Accreditation Council for Graduate Medical Education and the American Board of Medical Specialties Maintenance of Certification competencies for Patient Care and Medical Knowledge.
31. Snover DC, Phillips G, Dehner LP. Reactive fibrohistiocytic proliferation simulating fibrous histiocytoma. Am J Clin Pathol. 1981 Aug;76(2):232-235. doi: 10.1093/ajcp/76.2.232.

Specialties Maintenance of Certification competencies for Patient Care and Medical Knowledge. 